\title{
The Relationship Between Obesity, Overweight, and the Human Development Index in World Health Organization Eastern Mediterranean Region Countries
}

\author{
Amin Ataey ${ }^{1}$, Elnaz Jafarvand ${ }^{2}$, Davoud Adham ${ }^{3}$, Eslam Moradi-Asl ${ }^{3}$ \\ ${ }^{1}$ Meshkin Shahr Health Center, Ardabil University of Medical Sciences, Ardabil, Iran; ${ }^{2}$ Department of Community Nutrition, School of Nutritional Sci- \\ ences and Dietetics, Tehran University of Medical Sciences, Tehran, Iran ; ${ }^{3}$ Department of Public Health, School of Public Health, Ardabil University of \\ Medical Sciences, Ardabil, Iran
}

Objectives: Obesity is regarded as one of the most prominent health threats worldwide and a serious risk factor for non-communicable diseases, such as diabetes mellitus type 2, high blood pressure, cardiovascular diseases, and some types of cancer. Given the role that societal development—as reflected by the Human Development Index (HDI)—may play in the prevalence of obesity and overweight, this study aimed to investigate the degree to which the prevalence of obesity and overweight is affected by HDI and its components.

Methods: In this ecological study, the required data on HDI and its components were gathered from the latest report of the United Nations Development Program, and data on obesity and overweight were acquired from the latest reports published on the World Health Organization website. Statistical analyses were conducted using SPSS version 24.0.

Results: The prevalence of obesity was determined to be significantly higher among females than males, and the gross national index per capita was found to be significantly higher for males than females $(p<0.05)$. Significant positive correlations were found between $\mathrm{HDI}$ and its components and sex, as well as indices of obesity and overweight.

Conclusions: A significant positive correlation exists between $\mathrm{HDI}$ and obesity. As policy-makers attempt to improve the general welfare of the people, they should be aware of potential unwanted effects of development on the risk of obesity and overweight among the population.

Key words: Obesity, Overweight, Human Development Index, Eastern Mediterranean Region

\section{INTRODUCTION}

Overweight and obesity are among the main factors that

Received: April 30, 2019 Accepted: December 27, 2019

Corresponding author: Eslam Moradi-Asl, PhD Department of Public Health, School of Health, Ardabil University of Medical Sciences, Daneshgah Street, Ardabil 5618953141, Iran E-mail: E.moradias।@arums.ac.ir

This is an Open Access article distributed under the terms of the Creative Commons Attribution Non-Commercial License (https://creativecommons.org/licenses/by$\mathrm{nc} / 4.0 /$ ) which permits unrestricted non-commercial use, distribution, and reproduction in any medium, provided the original work is properly cited. contribute to non-communicable diseases (NCDs), such as diabetes mellitus type 2 , high blood pressure, cardiovascular diseases, some types of cancers, and musculoskeletal disorders [1]. According to a report published by the World Health Organization (WHO) in 2014, around 1.9 billion adults (people over 18 years of age) were overweight, and more than 600 million were obese [2]. It is expected that by 2030, more than 2.16 billion people will be overweight and 1.12 billion obese [3]. For 
this reason, obesity is considered an overt threat to public health around the globe. Research has shown that obesity and an increase in waist circumference can escalate the risk of NCDs, such as diabetes mellitus type 2 and cardiovascular disease $[4,5]$. Therefore, one of the aims of the WHO 2013-2020 Global Action Plan to prevent and control NCDs is to stop the rise in obesity by the year 2025 [6].

In addition to the impact of obesity on disease, the economic effects of obesity on families, healthcare systems, and the global economy are considerable. The direct medical costs of obesity include those for the prevention, diagnosis, and treatment of obesity and related diseases. In general, European countries allocate approximately $2-8 \%$ of their healthcare budgets to obesity, equaling about $0.6 \%$ of their gross national income (GNI) per capita. Based on data gathered in the United States in 2008, it has been speculated that overweight and obesity consume US\$147 billion in overall medical costs. To make matters worse, the indirect costs of overweight and obesity are clearly higher what has been reported. The direct and indirect costs of obesity may include the loss of a decent salary, the loss of vocational opportunities through the limitation of physical capabilities, the incidence of diseases, and early death. In fact, obesity is becoming a pandemic around the world and will cause unprecedented health, economic, and social tensions unless urgent measures are taken to change this trend [7].

The Human Development Index (HDI) categorizes countries among 3 levels of development based on data reported by the United Nations Development Program. This index is determined by 3 factors: long and healthy life, possession of knowledge, and standard of living. The criterion of a long and healthy life is based on the life expectancy index, possession of knowledge is measured by the mean of years of education and by expected years of education, and standard of living is measured by the GNI per capita [8]. Various studies have revealed a positive correlation between $\mathrm{HDI}$ and many chronic diseases, such as different types of cancer $[9,10]$ and anemia [11]. Similarly, the level of development of societies can affect factors that contribute to obesity. Given the possible role of $\mathrm{HDI}$ in the prevalence of obesity and overweight, this study set out to investigate the relationship of the standard prevalence of obesity and overweight in males and females with $\mathrm{HDI}$ and its components in countries in the WHO Eastern Mediterranean Region (EMR). Since factors such as income inequality, educational background, and availability of healthcare servic- es and centers may affect obesity, this study investigated the relationship of HDI (as well as its components) with obesity and overweight.

\section{METHODS}

This ecological study investigated the relationship of the standard prevalence of obesity and overweight in both males and females with HDI and its components (life expectancy, mean number of years of education and expected years of education, and GNI per capita) in EMR countries. The HDI data were gathered from 2 data sources: the latest report from the United Nations [8] regarding body mass index (BMI) and the latest report from the WHO website [12] regarding the standard prevalence of overweight and obesity in adults (18 years of age or older) based on sex. On the BMI scale, a BMI equal to or above $25.0 \mathrm{~kg} / \mathrm{m}^{2}$ constitutes overweight, and a BMl equal to or above $30.0 \mathrm{~kg} / \mathrm{m}^{2}$ constitutes obesity.

The EMR includes the following 22 countries: Cyprus, United Arab Emirates, Qatar, Saudi Arabia, Bahrain, Oman, Kuwait, Islamic Republic of Iran, Lebanon, Tunisia, Jordan, Libya, Egypt, Iraq, Morocco, Pakistan, Syrian Arab Republic, Sudan, Afghanistan, Djibouti, Yemen, and Somalia. Statistical analysis was conducted using SPSS version 24.0 (IBM Corp., Armonk, NY, USA). In order to assess the relationships of BMI, obesity, and overweight with $\mathrm{HDI}$ and its components, the Pearson correlation coefficient was calculated, with $p$-values of less than 0.05 considered to indicate statistical significance.

\section{Ethics Statement}

This study is not subject to ethical review as it is conducted using public data of 2018 report from the United Nations and latest report from the WHO (published in 2018).

\section{RESULTS}

Information obtained from the 22 EMR countries was analyzed. As observed in Figure1 and Table 1, there were statistically significant differences between males and females with regard to obesity and GNI per capita; in particular, the prevalence of obesity was higher in females than in males, and the GNI per capita was higher for males than for females $(p<0.05)$. Figures 2 and 3 show the estimated GNI per capita and the prevalence of obesity, respectively, in females and males in EMR countries. The highest prevalence of obesity and over- 


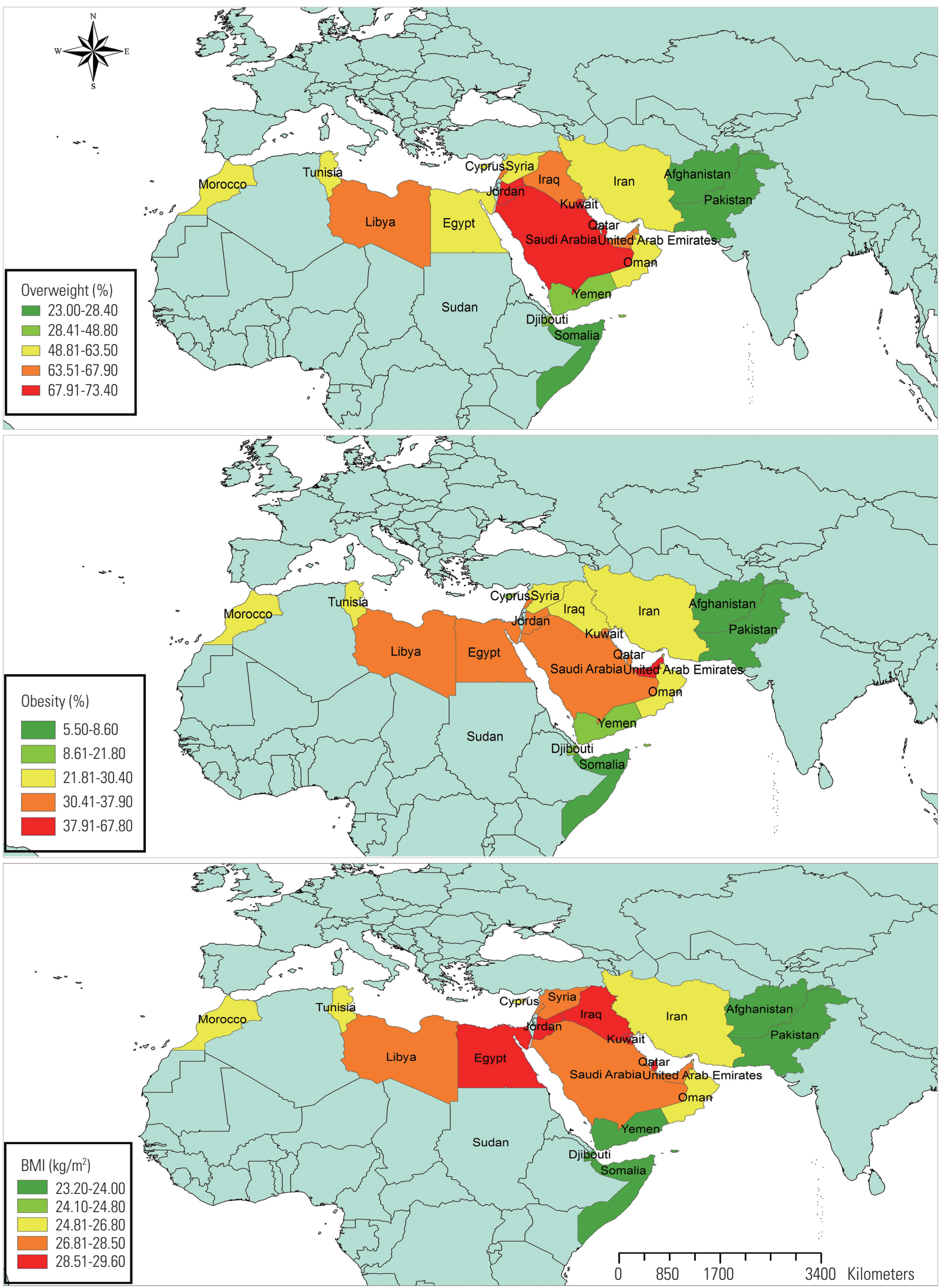

Figure 1. The status of overweight, obesity and body mass index (BMI) in Eastern Mediterranean Region countries, 2018. 
Table 1. Overweight, obesity, BMI, and HDI based on sex in EMR countries in 2018

\begin{tabular}{|c|c|c|c|}
\hline Variables & Sex & Mean \pm SD & $p$-value \\
\hline \multirow[t]{3}{*}{ Overweight (\%) } & Male & $54.95 \pm 16.49$ & 0.223 \\
\hline & Female & $60.89 \pm 14.56$ & \\
\hline & Total & $57.84 \pm 15.17$ & \\
\hline \multirow[t]{3}{*}{ Obesity (\%) } & Male & $20.64 \pm 9.05$ & 0.001 \\
\hline & Female & $31.76 \pm 11.52$ & \\
\hline & Total & $25.75 \pm 9.69$ & \\
\hline \multirow[t]{3}{*}{$\mathrm{BMI}\left(\mathrm{kg} / \mathrm{m}^{2}\right)$} & Male & $26.19 \pm 2.13$ & 0.103 \\
\hline & Female & $27.37 \pm 2.43$ & \\
\hline & Total & $26.19 \pm 2.13$ & \\
\hline \multirow[t]{3}{*}{$\mathrm{HDI}$} & Male & $0.74 \pm 0.12$ & 0.054 \\
\hline & Female & $0.65 \pm 0.18$ & \\
\hline & Total & $0.70 \pm 0.14$ & \\
\hline \multirow{3}{*}{$\begin{array}{l}\text { Life expectancy at } \\
\text { birth (y) }\end{array}$} & Male & $70.46 \pm 6.53$ & 0.070 \\
\hline & Female & $74.46 \pm 6.46$ & \\
\hline & Total & $72.15 \pm 6.35$ & \\
\hline \multirow{3}{*}{$\begin{array}{l}\text { Expected years of } \\
\text { education (y) }\end{array}$} & Male & $12.43 \pm 2.64$ & 0.792 \\
\hline & Female & $12.18 \pm 3.37$ & \\
\hline & Total & $12.28 \pm 2.89$ & \\
\hline \multirow{3}{*}{$\begin{array}{l}\text { Mean years of } \\
\text { education (y) }\end{array}$} & Male & $7.99 \pm 2.14$ & 0.406 \\
\hline & Female & $7.26 \pm 3.21$ & \\
\hline & Total & $7.44 \pm 2.65$ & \\
\hline \multirow{3}{*}{$\begin{array}{l}\text { Estimated GNI per capita } \\
\text { (2011 PPP US\$) }\end{array}$} & Male & $34071.57 \pm 35957.31$ & 0.011 \\
\hline & Female & $11497.67 \pm 15156.44$ & \\
\hline & Total & $25244.81 \pm 29775.60$ & \\
\hline
\end{tabular}

BMI, body mass index; HDI, Human Development Index; EMR, Eastern Mediterranean Region; SD, standard deviation; GNI, gross national income; PPP, purchasing power parity. weight in females and males was observed in Kuwait, in which the obesity prevalence rates were $45 \%$ and $33 \%$ in females and males, respectively, while the overweight prevalence rates in females and males were $75 \%$ and $72 \%$, respectively. The mean $\mathrm{HDI}$ was lower for females than for males $(0.65$ and 0.74 , respectively). However, the mean life expectancy was higher in females than in males ( 74 years for females and 70 years for males). The 2 educational indices (mean number of years of education and expected number of years of education) were not statistically significantly different between the sexes and had approximate values of 7 and 12, respectively. The GNI per capita (purchasing power parity US\$) was 11497 for females and 34071 for males.

The results of the statistical analysis shown in Table 2 reveal a significant positive correlation between HDI and its components and the obesity and overweight indices in females and males. As such, higher life expectancy was associated with higher numbers of years of education and expected years of education in both females and males, as well as obesity, overweight, and BMI $(p<0.05)$. Similarly, we found a significant positive correlation between the total per capita income and the prevalence of obesity and overweight $(p<0.05)$. Nevertheless, no significant correlation was observed among BMI, HDI, mean number of years of education, and GNI per capita in females. Likewise, no significant correlation was observed between life expectancy and BMI.

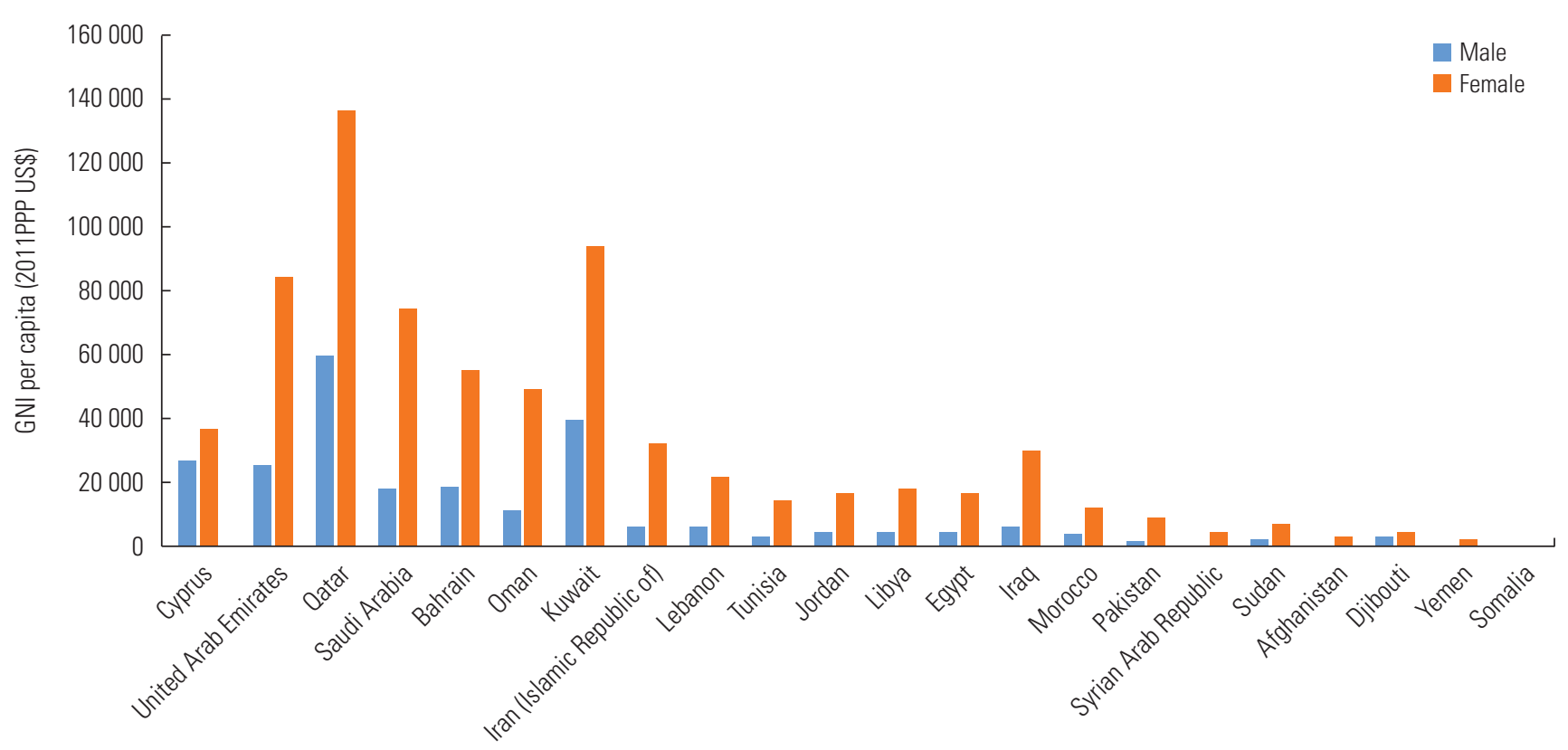

Figure 2. Estimated of gross national income (GNI) per capita in Eastern Mediterranean Region countries in 2018. PPP, purchasing power parity. 


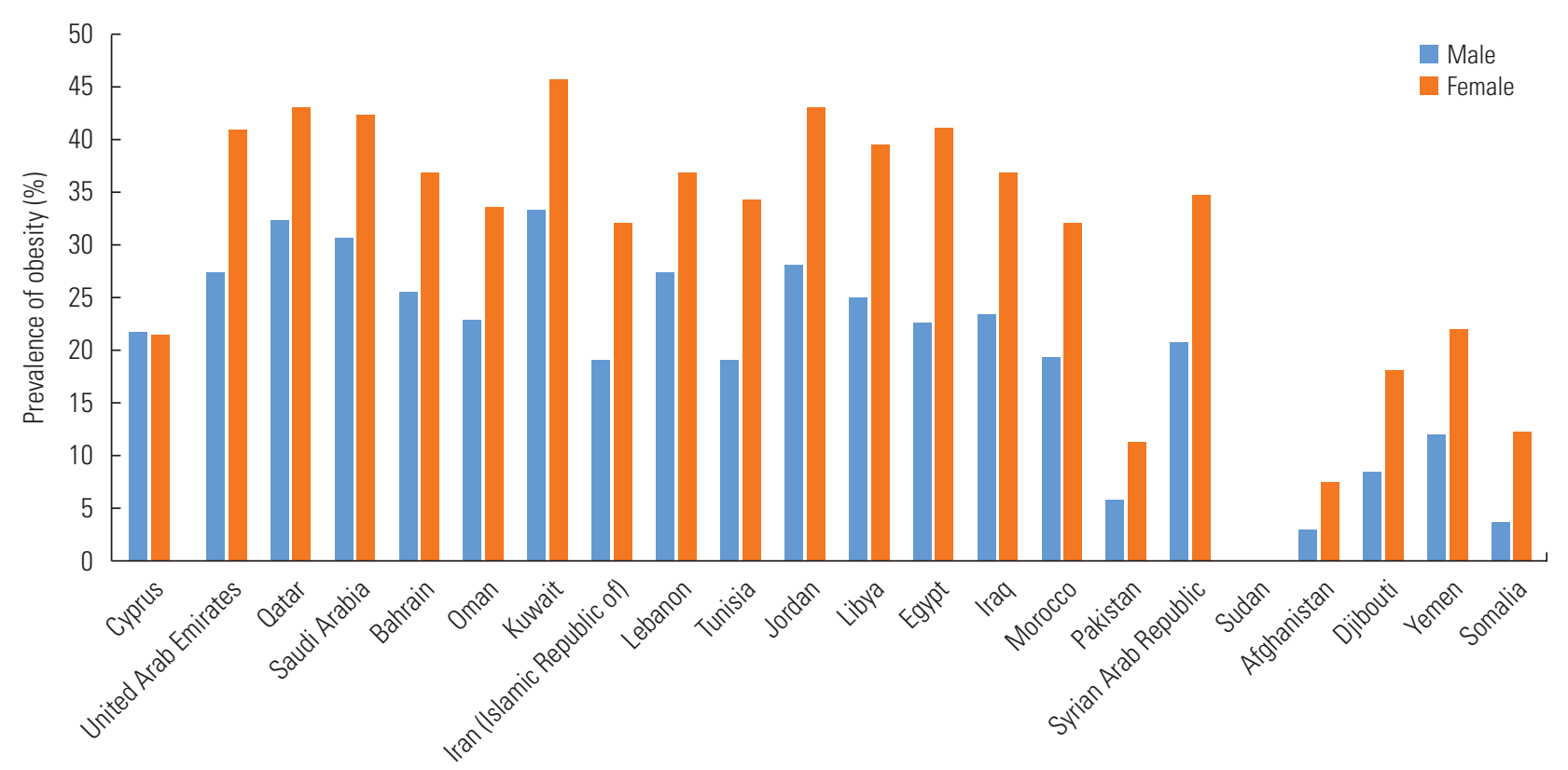

Figure 3. Age-standardized prevalence of obesity in Eastern Mediterranean Region countries in 2018.

Table 2. Correlation between overweight, obesity, BMI and HDI in Eastern Mediterranean Regional countries in 2018

\begin{tabular}{|c|c|c|c|c|c|c|}
\hline Index & HDI & $\begin{array}{l}\text { Life expectancy } \\
\text { at birth }\end{array}$ & $\begin{array}{l}\text { Expected years } \\
\text { of schooling }\end{array}$ & $\begin{array}{l}\text { Mean years of } \\
\text { schooling }\end{array}$ & $\begin{array}{l}\text { Estimated gross national } \\
\text { income per capita }\end{array}$ & $\begin{array}{c}\text { GNI } \\
\text { per capita }\end{array}$ \\
\hline \multicolumn{7}{|l|}{ Male } \\
\hline Overweight (\%) & $0.721(<0.001)$ & $0.842(<0.001)$ & $0.568(0.009)$ & $0.516(0.024)$ & $0.601(0.005)$ & $0.567(0.009)$ \\
\hline Obesity (\%) & $0.714(0.001)$ & $0.795(<0.001)$ & $0.559(0.010)$ & $0.446(0.056)$ & $0.703(0.001)$ & $0.666(0.001)$ \\
\hline BMI $\left(\mathrm{kg} / \mathrm{m}^{2}\right)$ & $0.549(0.015)$ & $0.683(0.001)$ & $0.385(0.093)$ & $0.372(0.116)$ & $0.583(0.007)$ & $0.559(0.010)$ \\
\hline \multicolumn{7}{|l|}{ Female } \\
\hline Obesity (\%) & $0.617(0.005)$ & $0.719(<0.001)$ & $0.710(<0.001)$ & $0.508(0.026)$ & $0.428(0.060)$ & $0.511(0.021)$ \\
\hline BMI $\left(\mathrm{kg} / \mathrm{m}^{2}\right)$ & $0.436(0.062)$ & $0.545(0.011)$ & $0.463(0.040)$ & $0.303(0.207)$ & $0.374(0.104)$ & $0.418(0.066)$ \\
\hline
\end{tabular}

The value in parentheses is presented as $p$-value.

$\mathrm{BMI}$, body mass index; HDI, Human Development Index; GNI, gross national income.

\section{DISCUSSION}

Obesity is caused by a positive energy balance in the body resulting from factors such as high energy consumption (via eating large portions or consuming foods of high energy density) or low physical activity. Such factors are usually a result of Westernization and ample economical wealth, as shown by the high frequency of obesity in Western industrial countries. Public health strategies implemented to prevent obesity have proved poorly effective. Worldwide, the number of overweight people is currently considerably higher than the number of underweight people [12]. Although personal obesity treatments have been found useful to a certain extent, it has been challenging to find the best method to overcome this health problem globally. Therefore, the identification of effective policies to counter obesity in societies is an international priority.

In line with the findings of previous research $[13,14]$, the results of this study show that the prevalence of obesity was higher among females than males. The higher obesity rate among females may result from early marriage, the secretion of sex hormones, a relative lack of physical activity, or the presence of certain neurological disorders, such as depression [15]. As stated by Musaiger [16] in his systematic review of EMR countries, obesity has reached a critical state in all countries in this region. Several factors are at play in this regard: nutritional transition, lethargy, urbanization, marital status, short breast- 
feeding span, frequent snacking, skipping breakfast, drinking excessive amounts of sweet drinks, eating out in restaurants, eating in front of the television, the improved marketing of high-fat foods, short stature, body image, cultural variables, and food subsidy policies [16].

The findings of this study show a significant positive relationship between the GNI per capita and the prevalence of obesity and overweight in both females and males. This finding agrees with the results of previous studies by Wells et al. [17] and $\mathrm{Ng}$ [18], which reported a significant positive relationship between the GNI per capita and the prevalence of obesity in both sexes. Industrialization was followed by increased income, lethargy, and changes in nutritional habits toward eating fast, fattier food. Moreover, urbanization also had an impact on the facilitation of the obesity process in different societies. $\mathrm{Ng}$ [18] reported a negative correlation between overweight and the number of rural inhabitants in a society. The current study showed that the mean HDI was lower for females than for males, while the life expectancy was higher for females than for males; however, the mean number of years of education and expected years of education were not statistically significantly different between the sexes.

The GNI per capita was 3 times lower for females than males, resulting in a lower HDI in females in spite of their higher life expectancy. Based on data collected in the 1990s, an international comparison of the obesity rate in females showed that in underdeveloped countries, obesity was dependent on the gross national product and the socioeconomic characteristics of the population [19]. The economic inequality in industrial countries (the Gini index) has a positive correlation with the obesity rate, and countries with the highest degree of inequality have experienced the highest prevalence of obesity [20]. Obesity is impacted not only by personal factors but also by an array of socioeconomic factors.

The analysis of the recent changes in developing and developed countries demonstrate that, in most cases, obesity is remarkably prevalent in economically successful countries. Nevertheless, in some cases, the fastest growth in the obesity rate has been observed in countries with low socioeconomic status. Clearly, there is no simple relationship between obesity and economic wealth, either within or among countries. Thus, given the effects of a globalized economy, we must take an international stand and investigate how the globalization of the economy has affected the prevalence of obesity.

One important factor is the extent to which males and fe- males, under the influence of socioeconomic factors, can experience obesity risks differently. Females may be more resilient than males to famine and are more susceptible to obesity. Hence, females may be more sensitive than males to the contemporary prevalence of obesity. Sex-based inequality is common, and is usually accompanied by discrimination, destitution, and relatively poorer healthcare. The analyses conducted in this study demonstrate that sex differences can have profound impacts on the prevalence of obesity and economic issues. The obesity rate, however, was not similar among the countries examined; rather, it was found to be higher in the countries that exhibit serious sex inequality [21]. These findings appear to reveal that the improvement of female's socioeconomic and healthcare conditions can be regarded as an effective treatment targeting obesity in females.

Research has shown that the BMI of females is generally higher than that of males in developing countries [21]. For example, Ferretti and Mariani [22] observed that the ratio of obesity in females to that in males is directly related to sex inequality, and similarly, the prevalence of obesity is affected by sex inequality. More than 2 decades of research (from 1990 to 2011) has revealed that the prevalence of obesity has reached a critical rate in EMR countries. The prevalence of overweight in preschool students (5 years of age) has been reported to range from $1.9 \%$ to $21.9 \%$, whereas the prevalence of overweight and obesity in school-aged students ranged from $7.0 \%$ to $45.0 \%$. Among adults, the prevalence of overweight and obesity ranged from $25.0 \%$ to $81.9 \%$.

It is obvious that the widespread prevalence of obesity is a global issue. However, it is impossible for all countries to tackle this problem in the same way. The overall findings of this study reveal that life expectancy, education level, and standard of living are significantly associated with overweight and obesity. This study is an ecological study that utilized data published by the WHO and the World Bank. This study has some limitations. First, in such studies, there may be no relationship present at the individual or the community level. These types of studies provide only a general view of society, and the relationships observed cannot be extrapolated to other populations. It is necessary to plan and conduct studies more specifically focused on certain relationships in order to generalize the relationships observed at the community level.

However, based on the findings, although it can be inferred that an increase in $\mathrm{HDI}$ is associated with increased prevalence of obesity, it is not accurate that policy-makers should slow 
down the process of development in their countries. Policymakers must be aware that as they attempt to improve the welfare of the people, they should also be cautious about some side effects of development, such as obesity. Overall, this study pinpoints the necessity of developing strategies and roadmaps that can bring about welfare improvements to society while improving the healthcare available to the people.

\section{CONFLICT OF INTEREST}

The authors have no conflicts of interest associated with the material presented in this paper.

\section{FUNDING}

None.

\section{ACKNOWLEDGEMENTS}

None.

\section{AUTHOR CONTRIBUTIONS}

Conceptualization: AA, EMA. Data curation: DA, EMA, EJ. Formal analysis: EMA, AA. Funding acquisition: None. Methodology: EMA, AA. Visualization: EMA, EJ, DA. Writing - original draft: EMA, AA. Writing - review \& editing: DA, EJ, EMA.

\section{ORCID}

Amin Ataey https://orcid.org/0000-0003-0842-250X

Elnaz Jafarvand https://orcid.org/0000-0003-0668-5859

Davoud Adham https://orcid.org/0000-0002-9764-6363

Eslam Moradi-Asl https://orcid.org/0000-0003-3999-6039

\section{REFERENCES}

1. Biswas T, Garnett SP, Pervin S, Rawal LB. The prevalence of underweight, overweight and obesity in Bangladeshi adults: data from a national survey. PLoS One 2017;12(5):e0177395.

2. World Health Organization. Obesity and overweight; 2016 [cited 2020 Feb 12]. Available from: https://www.who.int/newsroom/fact-sheets/detail/obesity-and-overweight.

3. Kolahi AA, Moghisi A, Soleiman Ekhtiari Y. Socio-demographic determinants of obesity indexes in Iran: findings from a nationwide STEPS survey. Health Promot Perspect 2018;8(3):187-194.

4. Stepaniak U, Micek A, Waśkiewicz A, Bielecki W, Drygas W, Janion $\mathrm{M}$, et al. Prevalence of general and abdominal obesity and overweight among adults in Poland. Results of the WOBASZ II study (2013-2014) and comparison with the WOBASZ study (2003-2005). Pol Arch Med Wewn 2016;126(9):662-671.

5. Alam DS, Talukder SH, Chowdhury MA, Siddiquee AT, Ahmed S, Pervin $\mathrm{S}$, et al. Overweight and abdominal obesity as determinants of undiagnosed diabetes and pre-diabetes in Bangladesh. BMC Obes 2016;3:19.

6. World Health Organization. Global action plan for the prevention and control of NCDs 2013-2020; 2013 [cited 2020 Feb 12]. Available from: https://www.who.int/nmh/publications/ncdaction-plan/en/.

7. Antwi F, Fazylova N, Garcon MC, Lopez L, Rubiano R, Slyer JT. The effectiveness of web-based programs on the reduction of childhood obesity in school-aged children: a systematic review. JBI Libr Syst Rev 2012;10(42 Suppl):1-14.

8. Nolan B. United Nations Development Programme. "Human development report 1998": how Ireland fares (book review). Econ Soc Rev 1998;29(3):304.

9. Rafiemanesh H, Mehtarpour M, Khani F, Hesami SM, Shamlou $R$, Towhidi $F$, et al. Epidemiology, incidence and mortality of lung cancer and their relationship with the development index in the world. JThorac Dis 2016;8(6):1094-1102.

10. Razi S, Ghoncheh M, Mohammadian-Hafshejani A, Aziznejhad $\mathrm{H}$, Mohammadian M, Salehiniya H. The incidence and mortality of ovarian cancer and their relationship with the Human Development Index in Asia. Ecancermedicalscience 2016;10: 628.

11. Petry N, Olofin I, Hurrell RF, Boy E, Wirth JP, Moursi M, et al. The proportion of anemia associated with iron deficiency in low, medium, and high human development index countries: a systematic analysis of national surveys. Nutrients 2016;8(11): 693.

12. World Health Organization. Global health observatory data repository [cited 2018 Sep 20]. Available from: http://apps.who. int/gho/data/?theme $=$ main .

13. Sibai AM, Hwalla N, Adra N, Rahal B. Prevalence and covariates of obesity in Lebanon: findings from the first epidemiological study. Obes Res 2003;11(11):1353-1361.

14. Campos G, Ryder E, Diez-Ewald M, Rivero F, Fernández V, Raleigh $\mathrm{X}$, et al. Prevalence of obesity and hyperinsulinemia: its association with serum lipid and lipoprotein concentrations 
in healthy individuals from Maracaibo, Venezuela. Invest Clin 2003;44(1):5-19 (Spanish).

15. Alwan A. Prevention and control of cardiovascular diseases. Alexandria: World Health Organization; 1995, p. 120-128.

16. Musaiger AO. Overweight and obesity in eastern mediterranean region: prevalence and possible causes. J Obes 2011;2011: 407237.

17. Wells JC, Marphatia AA, Cole TJ, McCoy D. Associations of economic and gender inequality with global obesity prevalence: understanding the female excess. Soc Sci Med 2012;75(3):482490.

18. $\mathrm{Ng} \mathrm{CD.} \mathrm{Global} \mathrm{analysis} \mathrm{of} \mathrm{overweight} \mathrm{prevalence} \mathrm{by} \mathrm{level} \mathrm{of}$ human development. J Glob Health 2015;5(2):020413.

19. Martorell R, Khan LK, Hughes ML, Grummer-Strawn LM. Obesity in women from developing countries. Eur J Clin Nutr 2000; 54(3):247-252.

20. Pickett KE, Kelly S, Brunner E, Lobstein T, Wilkinson RG. Wider income gaps, wider waistbands? An ecological study of obesity and income inequality. J Epidemiol Community Health 2005;59(8):670-674.

21. Maruyama S, Nakamura S. Why are women slimmer than men in developed countries? Econ Hum Biol 2018;30:1-13.

22. Ferretti F, Mariani M. Gender discrimination, gender disparities in obesity and human development. Heliyon 2017;3(3):e00263. 